\title{
An Introduction on the Laser Cladding Coatings on Magnesium Alloys
}

\author{
Ainhoa Riquelme *(D) and Pilar Rodrigo \\ Department of Applied Mathematics, Materials Science and Engineering and Electronics Technology, \\ Universidad Rey Juan Carlos, 28933 Madrid, Spain; pilar.rodrigo@urjc.es \\ * Correspondence: ainhoa.riquelme.aguado@urjc.es
}

check for updates

Citation: Riquelme, A.; Rodrigo, P.

An Introduction on the Laser Cladding Coatings on Magnesium Alloys. Metals 2021, 11, 1993. https://doi.org/10.3390/ met11121993

Academic Editor: Krzysztof Rokosz

Received: 16 November 2021

Accepted: 6 December 2021

Published: 9 December 2021

Publisher's Note: MDPI stays neutral with regard to jurisdictional claims in published maps and institutional affiliations.

Copyright: (c) 2021 by the authors. Licensee MDPI, Basel, Switzerland. This article is an open access article distributed under the terms and conditions of the Creative Commons Attribution (CC BY) license (https:// creativecommons.org/licenses/by/ $4.0 /)$.

\begin{abstract}
Magnesium alloys are a promising structural material to be used as a substitute for metals traditionally used in the automotive and aircraft sector. However, magnesium alloys have poor mechanical properties and corrosion resistance. These handicaps can be overcome through the application of coatings with improved properties. Laser cladding is a potential coating fabrication process. Furthermore, the low vaporization temperature of magnesium and the coating-substrate dilution problems increase the difficulty to coat magnesium substrates. The aim of this research is to analyze the state of art in magnesium laser cladding and investigate the effect of the most important fabrication parameters on the interaction of the different coating-substrate systems used on the mechanical properties and corrosion resistance. In addition, this work provides a guidance on laser cladding best practices for these alloys. Knowledge of how the different coating manufacturing parameters affect the final surface properties of magnesium alloys is essential for the implantation of these materials in applications for which they are currently limited.
\end{abstract}

Keywords: laser cladding; magnesium; coatings

\section{Introduction}

Magnesium alloys have a great potential to be used as a structural material due to their low density, which leads to very high specific mechanical properties, comparable to those of some steels. In addition, their ease of machining and low cost make them suitable alloys for use in the transportation industry. The main limitations of these alloys are the low surface properties, since they have low wear and corrosion resistance, reducing their field of application [1-3].

One of the strategies that can be followed to improve this limitation is to make protective surface coatings by laser cladding techniques. The main advantages that laser cladding offers compared to other more traditional techniques are better surface properties with minimal dilution, minimal substrate thermal distortion and better surface quality. To obtain coatings with good mechanical characteristics, it is necessary to select the appropriate process parameters for which it is necessary to know the effect that these have on the resulting coating. The effect of parameters such as laser power, scanning speed, powder feed, as well as the properties of both the substrate and the powder on the obtained coatings has led to several studies. The variation of any of these parameters turns into changes in the morphology, width or height, as well as in the metallurgical characteristics of the coating, microstructure, degree of dilution, porosity, etc. [4,5].

\section{Laser Alloying, Glazing, and Cladding}

Laser cladding is a coating manufacture method with which it is possible to obtain low porous and improved properties coatings on different materials (mainly metals) using a laser as energy source. Based on the feed material, the amount of molten substrate and the laser parameters, three varieties of this process can be established: laser alloying, laser glazing and laser cladding. In the three cases, the high cooling rate and, consequently the 
quick solidification during the fabrication process is the main advantage of these methods, because it results in a fine microstructure and improved mechanical properties. During the solidification process, the melted metal liquid atoms are joined together at the nucleation points and start to form crystals. These crystals grow and form grains in the direction of the solidification, however, due to the high cooling rates, these grains have no time to become bigger, and their size ends up being very small in this kind of process. Small grain sizes result in high number of grain limits and, consequently, in high hardness and mechanical properties [6].

Laser alloying technique allows to melt simultaneously the feeding material and the substrate obtaining a homogeneous alloyed metal. In general, the coating is not very thick because the amount of spraying material is low [7].

Laser glazing allows to melt only a small part of the substrate and cool it very quickly $\left(10^{10}-10^{12} \mathrm{~K} / \mathrm{s}\right)$, which forms amorphous crystal [8-11].

Coatings with different composition to the substrate have been successfully fabricated by Laser cladding technique since this method produces a minimum dilution of the substrate allowing the coating to maintain the feed material properties. Moreover, a fine coating microstructure is obtained due to the quick cool rate. To achieve this, the control of the laser parameters is very important.

The main problem of lasers techniques on magnesium alloys is that the use of magnesium as a substrate, together with high values of laser power, can produce a dilution of the magnesium from the substrate to within the coating matrix due to the low melting points of magnesium alloys $\left(\sim 560^{\circ} \mathrm{C}\right)$ that makes them liable to be melted during the laser cladding process. Nevertheless, this dilution changes with the processing parameters, therefore, obtaining a minimal dilution rate is possible. Indeed, the three methods of coatings fabrication (laser alloying, laser glazing and laser cladding) are feasible on magnesium alloys.

For instance, Ignat et al. [12] obtained hardened high corrosion resistance $\mathrm{Al} / \mathrm{Mg}$ coatings on WE43 and ZE41 magnesium alloys by laser alloying. Other authors such as Yue, Su, and Yang [8] and Huang et al. [9] developed amorphous coatings by laser glazing. However, avoiding dilution is possible by using low laser power. Yang et al. [13] used laser cladding to coat ZE91D magnesium alloys with $\mathrm{Al}+\left(\mathrm{Ti}+\mathrm{B}_{4} \mathrm{C}\right)$ composite coatings and A. H. Wang et al. [14] utilized laser cladding to repair surface areas of magnesium components.

Obtaining improved coatings with homogeneous compositions, low porosity, minimal interactions between the molten pool and the sprayed material, and greater properties depends on the laser parameters and on the amount of the feed material used. Indeed, most laser cladding coatings are actually laser alloying coatings.

Figure 1 shows a scheme of laser alloying, glazing and cladding. The classification is based on the mixed composition between the magnesium of the substrate and the elements of the coatings [6]. In addition, Figure 1 shows an example of the resulting microstructure. The main differences between the microstructure showed in Figure 1a,c is that in the case of laser alloying, there is a higher dilution between the coating and the substrate, and the resultant material is embedded in the substrate surface. In the case of the laser cladding microstructure, the coating is on the substrate surface, not embedded in the substrate. In the case of the laser glazing microstructure shown in Figure 1b, the morphology/shape of the coating is similar to laser cladding, however, the coating is an amorphous crystal. 
(a)

Laser Alloying
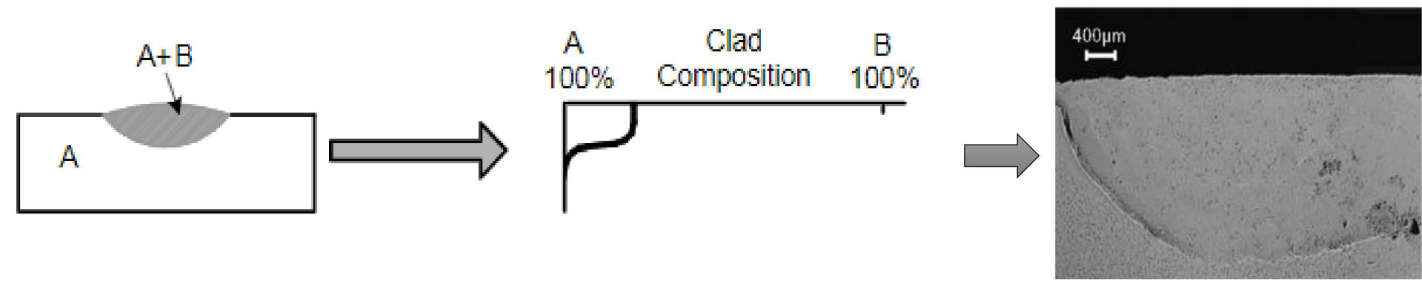

(b)

Laser Glazing

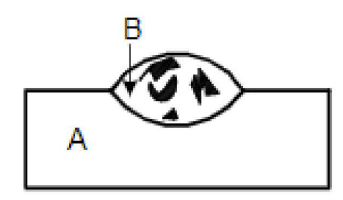

(c)
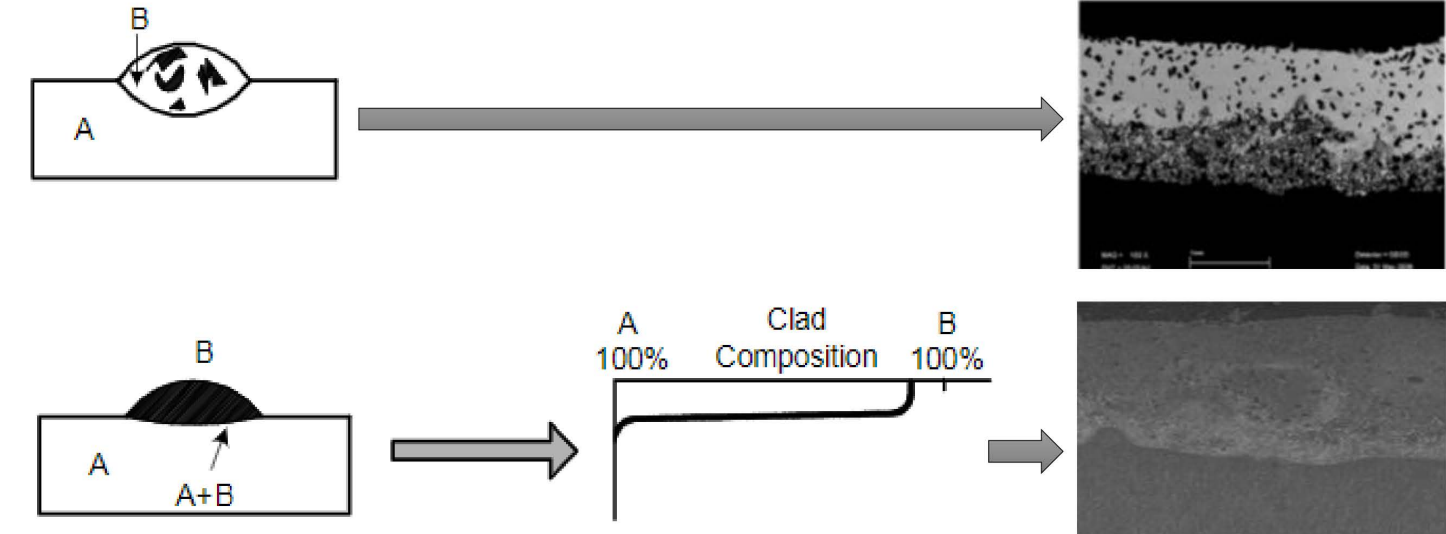

Laser Cladding

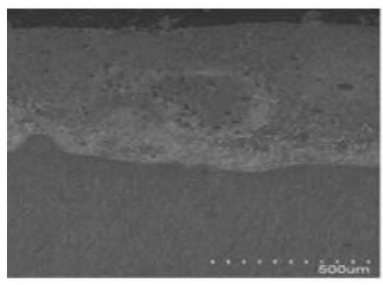

Figure 1. Scheme of laser alloying, glazing and cladding [6]; (a) Al laser alloying coating on ZE41. Reprinted with permission from ref. [7]. Copyright 2021 Elsevier; (b) 65Al7.5Ni10Cu17.5 reinforced with SiC particles amorphous coating on Mg substrate. Reprinted with permission from ref. [10]. Copyright 2021 Elsevier; (c) A12Si/SiC laser cladding coating on ZE41 alloy. Reprinted with permission from ref. [15]. Copyright 2021 Elsevier.

\section{Laser Cladding on Magnesium Alloys}

Laser cladding is an effective fabrication process to obtain surface layers with improved properties, good metallurgic bonding with lack of defects, and low dilution that can be achieved in comparison with conventional methods like thermal spraying or arc welding. The use of a laser as an energy source is key to these advantages.

Furthermore, from a manufacturing point of view, laser cladding has other benefits: decreasing manufacturing times; increasing cooling and solidification rates; no restrictions on the fabrication of complicated geometries and repair of components.

The coating process was carried out with a laser cladding system consisting of a laser (different kind of lasers are possible, for instance: diode laser $(848 \mathrm{~nm}), \mathrm{Nd}$ :Yag laser $(1064 \mathrm{~nm}), \mathrm{CO}_{2}$ laser $(10.64 \mu \mathrm{m})$, and excimer laser $\left.(248 \mathrm{~nm})\right)$. In most cases, the feeding material is in the form of spherical powder which is generally sprayed with a carrier gas (generally Argon) and coaxially with the laser beam trough a cladding nozzle (normally a coaxial nozzle). Moreover, other forms of feeding material are possible as is shown in Figure 2. For example, paste feeding (Figure 2a) when the raw material is in a paste shape, wire feeding (Figure 2c) when it is in a wire shape or preplaced powder, where the raw powder is previously deposited on the substrate surface, and then the laser passes over this powder and melts it, and a minimal part of the substrate surface forms the coating [6]. The laser with the cladding nozzle is connected to a motor control system, it generally consists of a CAD (computer-assisted draughting) system and a motion robot or a $x-y$ motion table. Figure 3 shows the scheme of an equipment of laser cladding [16]. 

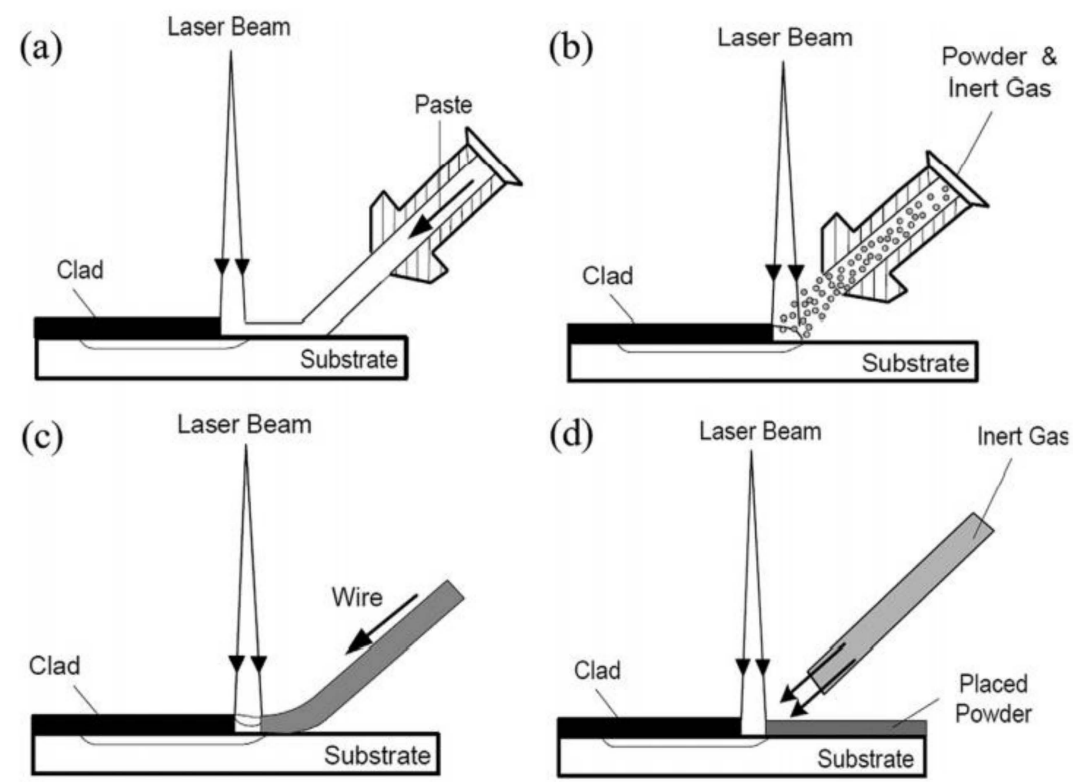

Figure 2. Different methods of laser cladding feeder: (a) paste feeding; (b) powder injection; (c) wire feeding; (d) preplaced powder [6].

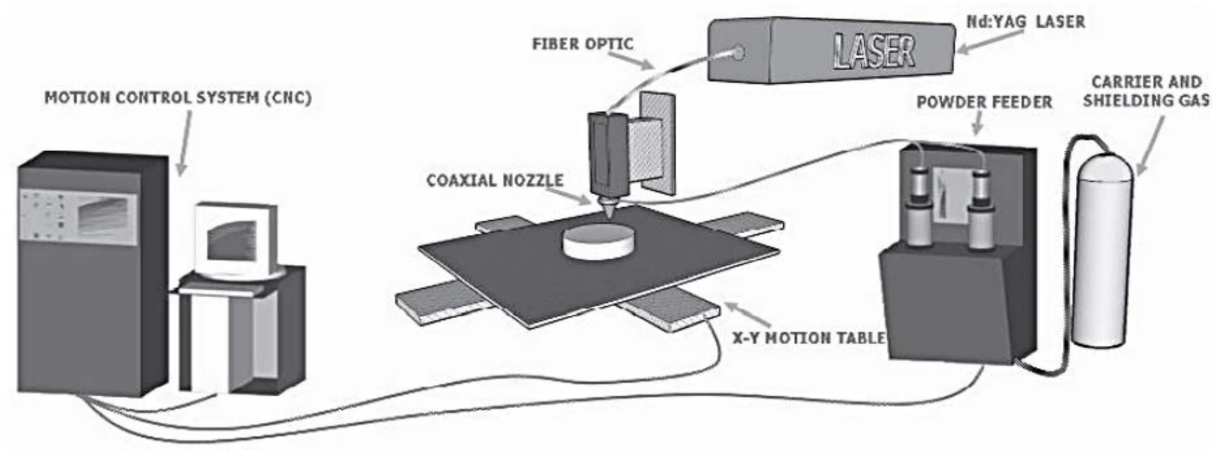

Figure 3. Scheme of laser cladding equipment. Reprinted with permission from ref. [16]. Copyright 2021 Elsevier.

\section{Effect of the Process Parameters}

The laser coating process is affected by a wide variety of parameters, as shown in Figure 4 [6].

\subsection{Effect of Inputs Parameters}

The effect of some control parameters are common for all materials but in some cases, an exhaustive analysis of these parameters is necessary for each kind of sprayed material and substrate. This review is partly focused on the study of the effect of these kinds of parameters.

Input parameters related to the laser energy source, which widely depend on the kind of coating and substrate, are laser power, scanning speed, beam focal position and the wavelength of the laser beam.

In general, the effect of laser power and scanning speed has been studied together because the energy density in the material during the cladding process is directly related to these parameters and, also to the laser spot size, following Equation (1) [17-19].

$$
\text { Energy Density }\left(\mathrm{J} / \mathrm{mm}^{2}\right)=\frac{\text { laser power }(\mathrm{W})}{\text { scanning speed }\left(\frac{\mathrm{mm}}{\mathrm{s}}\right) \cdot \text { Laser spot diameter }(\mathrm{mm})}
$$




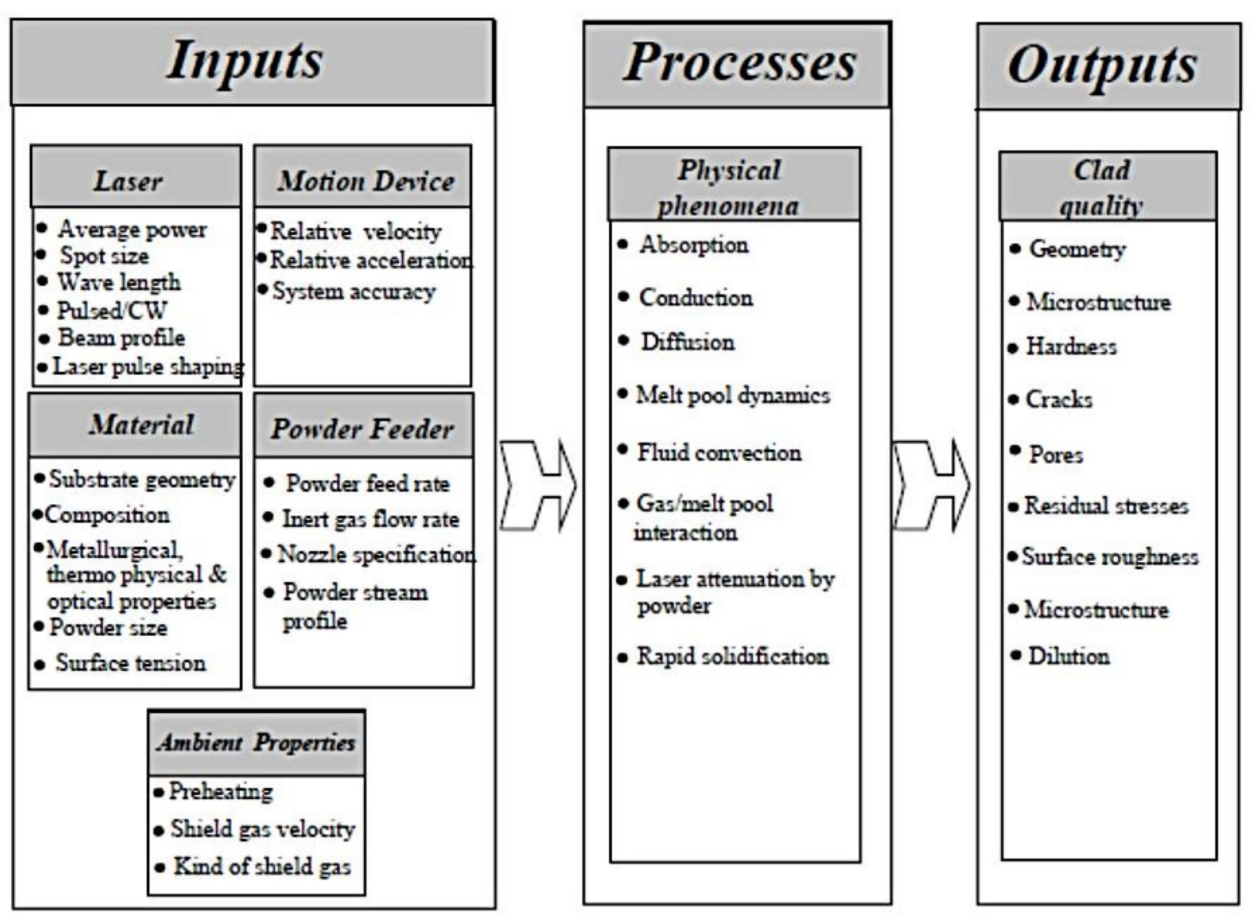

Figure 4. Inputs, outputs and process parameters of laser cladding [6].

The influence of these parameters has been widely researched. The effect of the scanning speed and the laser power is similar in all materials, and, in this sense, the characteristics of magnesium alloys, especially their low fusion temperature, make the study of these parameters especially suitable for understanding the laser cladding process. First studies about the effect of these parameters on magnesium alloys have been performed by Wang and Yue [20] who evaluated different scanning speeds and kept laser power constant. Liu et al. [21] analyzed the effect on the width of laser cladding $\mathrm{Al}$ coatings on AZ91D magnesium alloys. Recently, some authors have determined that laser cladding could be an effective fabrication process of metal matrix composite coatings. However, the study of the effect of the laser parameters on this kind of coating on magnesium alloys is scarce. In this sense, the effect of scanning speed and laser power on $\mathrm{Al} / \mathrm{SiCp}$ coatings on ZE41 magnesium alloys has been studied by Riquelme et al. [15] who observed that the geometry and properties of the coating depend on these parameters. All of these studies concluded that in order to obtain good quality coatings it is necessary to find the optimal combination of scanning speed and laser power (and this combination could be different for each kind of coating or magnesium alloy). In addition, considering that the scanning speed and the laser power are directly related to the molten pool size and the cooling rate, the importance of the heat and mass transferring process increases for this substrate because it affects considerably the microstructure due to the lower fusion temperature of magnesium alloys.

The different focal position to the substrate surface affects the coating geometry, dilution, melted and heat affected zones. There is only few research about this topic and even less about coatings on magnesium alloys. This issue was analyzed by Riquelme et al. [15]. These authors found that different beam focal positions produce different substrate-sprayed particles interactions, which leads to changes in the characteristics of the coatings. Figure 5 shows three types of focus modes. At negative defocus mode, the molten zone depth is higher, the coating is very thin and in some zones it did not cover the entire surface. At positive defocus mode, high dilution between the coating and the substrate is observed. At on focus mode, a minimal melted zone is appreciated and better coating characteristics have been obtained. 
(c)

(b)

(a)

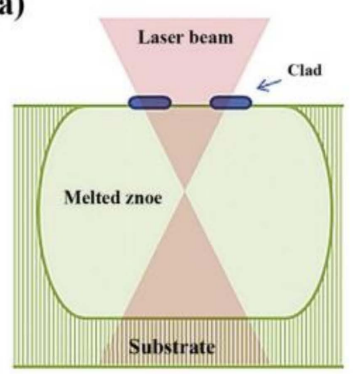

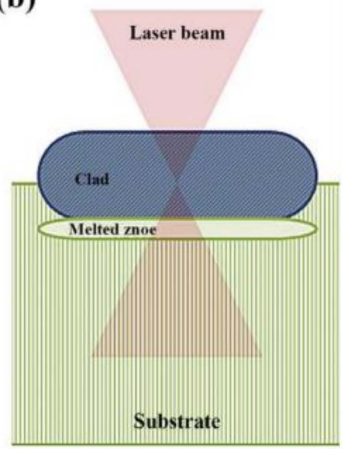

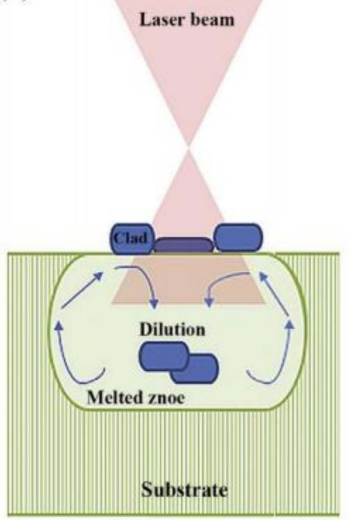

Figure 5. Schematic of laser beam-cladding coating interactions: (a) negative defocus; (b) on focus; (c) positive defocus. Reprinted with permission from ref. [15]. Copyright 2021 Elsevier.

Wavelength of the laser beam has important effects on the reflectivity-absorptivity of metals. The importance of measuring the absorbed energy is such that this energy affects the material transformation. Figure 6 shows the correlation between reflectivity and beam wavelength for different metals [6]. Some researchers showed that lasers with a shorter wavelength were more advantageous to be absorbed by metals [22].

(a)

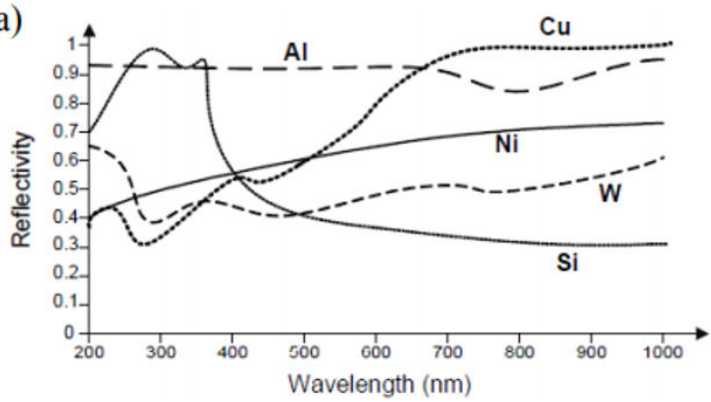

(b)

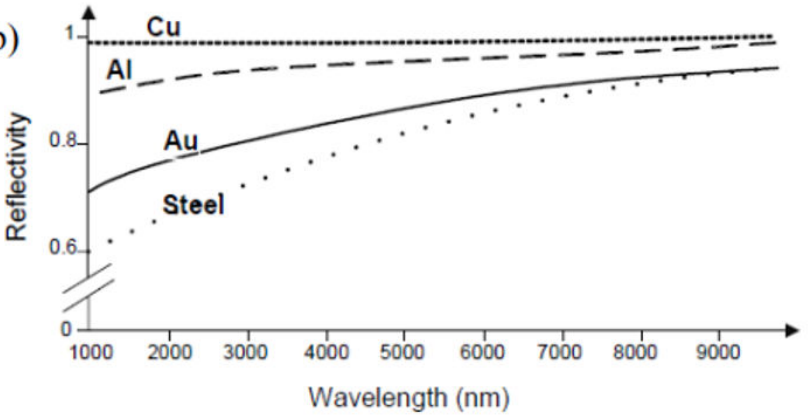

Figure 6. Correlation between reflectivity and beam wavelength for different metals, in two different wavelength ranges (a) 200 to $1000 \mathrm{~nm}$, (b) 1000 to $9000 \mathrm{~nm}$ [6].

Ignat et al. [12] analyzed the coupling effect between magnesium alloys (with anodising, or mordancage protective layers or without protective layers) and Nd:YAG laser beam. They found that the laser energy affects the percentage of absorption for the magnesium substrates. Figure 7 shows the absorption percentage as a function of the incident energy for treated and untreated WE43 (Figure 7a) and ZE41 (Figure 7b). Pre-treated materials had higher absorption rates than uncoated substrates.
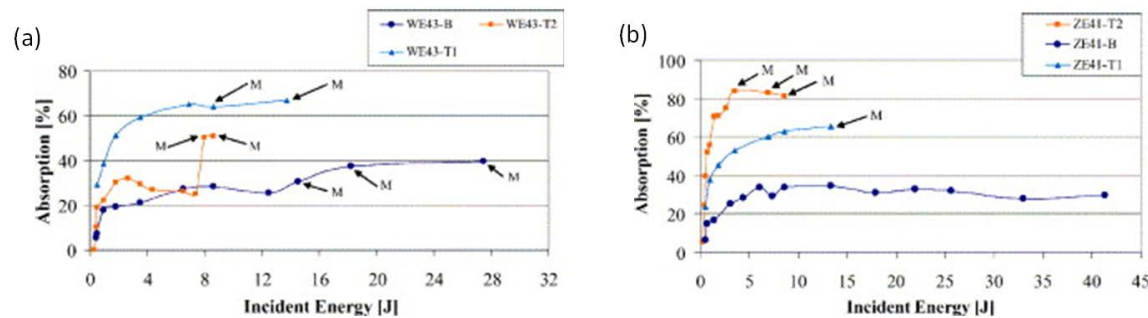

Figure 7. (a) absorption for WE43 magnesium alloy ( $\mathrm{B}=$ unpretreated; $\mathrm{T} 1$ = anodising treatment; $\mathrm{T} 2$ = mordancage treatment); (b) absorption for ZE41 magnesium alloy (B = unpretreated; $\mathrm{T} 1=$ anodising treatment; $\mathrm{T} 2$ = mordancage treatment). Reprinted with permission from ref. [12]. Copyright 2021 Elsevier. 
Knowing the energy absorption percentage in laser cladding techniques is crucial since the laser beam causes partial heats that are transmitted to the substrate, and then affects the distribution of absorbed energy between the cladding material and substrate. The energy absorbed by the substrate increases the dilution zone and it affects the coating microstructure and its properties.

Inputs parameters related to the coating feeding material such as the kind of laser cladding feeder have an influence in the characteristics of the coating and it depends on both the kind of substrate and the coating material. For example, Yue and $\mathrm{Su}$ [10] obtained Zr65Al7.5Ni10Cu17.5 coating on magnesium substrate using one-step laser cladding (powder injection) resulting in the formation of amorphous phases due to the higher quenching and cooling rates. Liu et al. [22] developed Al coatings on AZ31B magnesium alloy by the two-step process. Al powders were deposited on the surface of the substrate before laser processing. There appears to be more porosity in the coatings with this method.

Depending on the powder feed rate, the height of the coatings changed and the cooling rate at the top of the coating can be different than at the bottom, resulting in a variation in the microstructure along the coating $[16,23,24]$.

Other parameters related to the feeding material, such as the inert carrying gas flow rate and its effect on laser cladding coatings on magnesium, need to be researched.

\subsection{Effect of Outputs Parameters}

As is explained above, outputs laser cladding parameters depend on the inputs parameters, for example dilution rate, coating geometry, presence of cracks and pores are determined by principally the laser, motion device and feeding material parameters. Microstructure of the coatings also depends on these inputs parameters and in addition on the kind of cladding material system deposited on magnesium alloys.

When the objective of laser cladding is to repair the substrate, homogeneous magnesium coatings are deposited on the surface of magnesium components [14]. In this case, microstructure, grain size and form are subject to the laser parameters and the cooling rate. Nevertheless, the deposition of heterogeneous cladding materials is becoming more common. A possible classification of these coatings could be (i) pure metal, binary and ternary alloy coatings, (ii) high entropy alloy (HEA) coatings, (iii) ceramics coatings and (iv) metal matrix composite coatings.

\subsubsection{Pure Metal, Binary and Ternary Alloy Coatings}

The majority of pure metal, binary and ternary alloy coatings contain $\mathrm{Mg}$-Al because $\mathrm{Al}$ increases the $\mathrm{Mg}$ hardness; however, adding $\mathrm{Al}$ into $\mathrm{Mg}$ alloys worsens the corrosion behavior [7]. Other authors have added binary or ternary alloys to achieve improved wear and corrosion behavior. In all cases, the presence of Al results in that some of the phases obtained are formed according to the equilibrium Al-Mg phase diagram. In addition, the presence of other metals results in Al-metal or Mg-metal phases. The most widely researched binary alloy as laser cladding material on magnesium alloys was Al-Si alloys. The microstructure of these coatings was characterized by an Al-Mg matrix with embedded dendrite precipitates of $\mathrm{Mg}_{2} \mathrm{Si}$. In function of the laser scanning speed and, in consequence, in function of the cooling rates, the $\mathrm{Al}-\mathrm{Mg}$ matrix can be formed by a $\mathrm{Mg}$ solid solution in $\mathrm{Al}$ or by the $\mathrm{Mg}_{17} \mathrm{Al}_{12}$ intermetallic phase. This microstructure increases the hardness of the coating and, also, the substrate-coating dilution, thus, the reactivity results in a good metallurgy bonding. However, Volovitch et al. [25], who coated ZE41 magnesium alloys with Al-Si coatings and observed that these kind of coatings result in higher corrosion rates due to the formation of galvanic corrosion and conclude that to reduce the way to improve the corrosion resistance of these coatings are to achieve a homogeneous microstructure; at higher laser speeds the diffusion of $\mathrm{Mg}$ in the layer decreases and the formation of thermodynamically stable but corrosive $\mathrm{Mg}_{2} \mathrm{Si}$ dendrites can be prevented. Other authors observed similar results [26,27]. Nevertheless, an increase of the corrosion resistance using similar coatings has been detected by other authors. For example, Carcel et al. [16] 
deposited Al-Si coatings on AZ61, ZK30 and WE54 and Chen et al. [23] on Mg-Gd-Y-Zr alloys (in this case hardening $\mathrm{Al}_{2}(\mathrm{Gd}, \mathrm{Y})$ is also obtained). The different results may be caused by the changeable laser cladding parameters or the different $\mathrm{Si}$ weight ratio sprayed during each research work. Yang and $\mathrm{Wu}$ [28] researched the effect of the Si weight ratio in Si Al-Si coatings on AZ91D magnesium alloy. They found that $\mathrm{Mg}_{2} \mathrm{Si}$ phase increases with the increase of Si content. When the spraying material was $\mathrm{Al}-12.5 \mathrm{wt} \% \mathrm{Si}$ (eutectic alloy), the coating microstructure consists of $\mathrm{Mg}_{2} \mathrm{Si}$ phase side fine dendrite of $\mathrm{Mg}_{17} \mathrm{Al}_{12}$. When the spraying material was hypoeutectic, only a small amount of $\mathrm{Mg}_{2} \mathrm{Si}$ phase is formed. For hypereutectic coatings, the microstructure consists of high amounts of $\mathrm{Mg}_{2} \mathrm{Si}$ into slight $\mathrm{Mg}_{17} \mathrm{Al}_{12}$ dendrites. Furthermore, Qian et al. [29], achieved an Al-Si coating without $\mathrm{Mg}_{2} \mathrm{Si}$ phases using laser cladding in two steps (plasma-sprayed coating and laser-remelted coating) and using low laser power and high scanning speed. The absence of $\mathrm{Mg}_{2} \mathrm{Si}$ improves the corrosion behavior.

Other Al alloys have been used as laser cladding coatings on the magnesium substrates, as, for example, Al-Zn, Al-Cu or Al-Ir [30-32]. Al-Zn powders were thermally sprayed on a $\mathrm{ZK} 60 / \mathrm{SiC}$ composite and then remelted with a YAG laser. As a result, the corrosion potential of the coating sample was found to be approximately $300 \mathrm{mV}$ higher than that of the sample as received, while the corrosion current was at least three orders of magnitude lower [31].

Same as in the case of Al pure or Al-Si coating, the use of these binary alloys leads to a reactivity between the coating and the substrate. For example, $\mathrm{Al}-\mathrm{Cu}$ coatings manufactured by Gao et al. [30] were composed of an Al-Mg matrix and $\mathrm{AlCu}_{4}$ and $\mathrm{Mg}_{17} \mathrm{Al}_{12}$ intermetallic phase. In the case of Al-Ir, Chen et al. [32] observed the formation of AlIr, $\mathrm{Mgl}_{7} \mathrm{Al}_{12}$ and other Al-based phases.

In addition, ternary alloys can be used with laser cladding. Ti-Ni-Al [33], or Ni-Zr-Al coatings [34] have been successfully used. Other metals, such as stainless steel [35], between others, have been investigated in order to be used as laser cladding coatings on magnesium alloys, although to a minor extent.

\subsubsection{High Entropy Alloy (HEA) Coatings}

The utilization of high-entropy alloys (HEA) as laser cladding coatings has been researched. However, there are just few studies and few used alloys. AlCoCrCuFeNi coatings on pure magnesium have been investigated by Yue et al. [36] and Meng et al. [37-39]. In the two cases, there is a dilution between the coating and the substrate, thus, some $\mathrm{CuMg}_{2}$ dendrites were detected.

\subsubsection{Ceramics Coatings}

On the other hand, not only metals can be used as laser cladding coatings. Some authors have achieved the fabrication of ceramic coatings on magnesium alloys, in order to improve the wear and corrosion behavior of the substrate. Ceramics have a low affinity to react with the magnesium substrate and tend to form other compounds, however, they can also refine the substrate microstructure and improve the corrosion and wear resistance. If the coating has low porosity and there are not paths from the surface to the substrate, the corrosion resistance of the entire system can be very high. Moreover, the ceramics compression resistance and hardness are higher than metals, so these materials used as coating improved these mechanical properties and wear resistance of the magnesium substrates. Gao et al. [40] developed this kind of coating and achieved improved properties with $\mathrm{Al}_{2} \mathrm{O}_{3}$ coating on AZ91HP Mg alloy.

\subsubsection{Metal Matrix Composite Coatings}

Up to now, different approaches have been investigated in the field of metal matrix composite cladding on magnesium alloys. In some studies, ceramic materials are used as reinforcement to obtain a wear resistant coating. Nevertheless, ceramic materials in magnesium matrixes gave rise to poor interfacial strength and poor corrosion resistance [41,42]. 
The most researched matrixes of these composite coatings (fabricated by laser cladding on magnesium alloys) are aluminum-based alloys, and the most used ceramic reinforcements have particle morphology, because of these composite coatings combine improved tribological properties with a considerably high corrosion resistance [16]. Some studies have evaluated coatings on magnesium alloys and wear properties of aluminum-based alloys or aluminum-based metal composites. For example, $\mathrm{Al}+\left(\mathrm{Ti}+\mathrm{B}_{4} \mathrm{C}\right)$ composite coatings on ZE91D magnesium alloys have been obtained by laser cladding by Yang et al. [13]. These authors determined that in this kind of coating there is some reactivity between the coating and the substrate and that $\mathrm{Al}_{3} \mathrm{Mg}_{2}, \mathrm{Al}_{12} \mathrm{Mg}_{17}, \mathrm{Al}_{3} \mathrm{Ti}$ and $\mathrm{TiC}$ compounds were observed in the coating microstructure. In order to avoid dilution, it is necessary to use low laser power, and this results in improved wear and corrosion resistance coatings.

However, the most used reinforcement is $\mathrm{SiC}$ and $\mathrm{Al}_{2} \mathrm{O}_{3}$ particles. The microstructure and properties of $\mathrm{Al} / \mathrm{SiC}$ coatings on AZ91D magnesium alloy using pulse-laser (Nd-YAG) have been analyzed by Zheng et al. in 2010 and 2014 [41,43]. The surface hardness and the wear resistance of the coatings are greater than those of the substrate and increase with the increment in the $\mathrm{SiC}$ content. As in the case of Yang et al. [13] coatings, a dilution takes place and $\mathrm{Al}_{12} \mathrm{Mg}_{17}$ phase is formed. The reaction mechanisms and the analysis of the obtained microstructure with different composition of $\mathrm{Al} / \mathrm{SiC}$ coatings on $\mathrm{ZE} 41$ magnesium alloy have been determined by Riquelme et al. [24] as is shown in Figure 8. The dilution problems cannot be avoided for any laser cladding parameter of scanning speed or laser power, so, the use of different alloying elements was introduced in order to avoid the reactivity between the aluminum matrix and the substrate and to obtain compounds with improved properties. The effect of these compounds was analyzed by the same authors in 2021. Despite the wear resistance of these kind of coatings being higher than the magnesium substrate, the corrosion resistance is worse due to the formation of micro cells as a result of the dilution between the substrate and the coating during the coating fabrication process [44]. Other authors continue with this line of work [45].

(a)

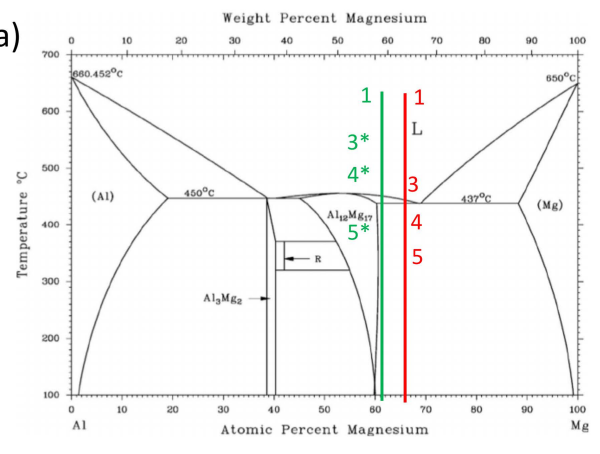

(b)

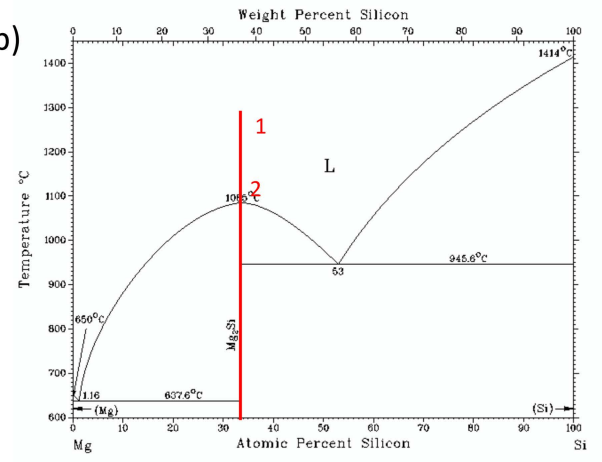

(c) (1)

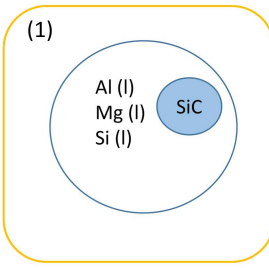

(d)

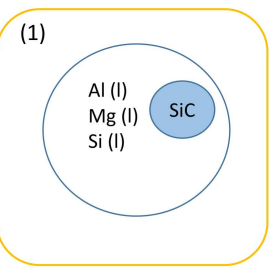

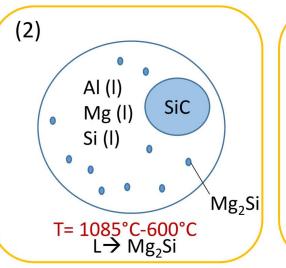

(2)

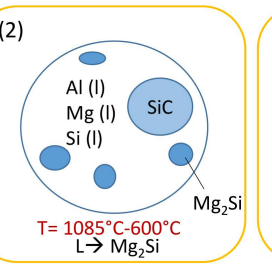

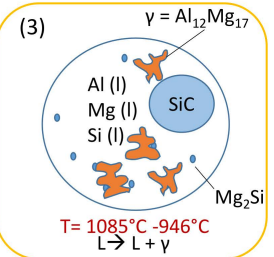

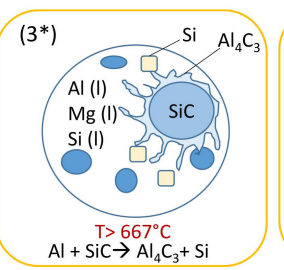

Figure 8. Cont.
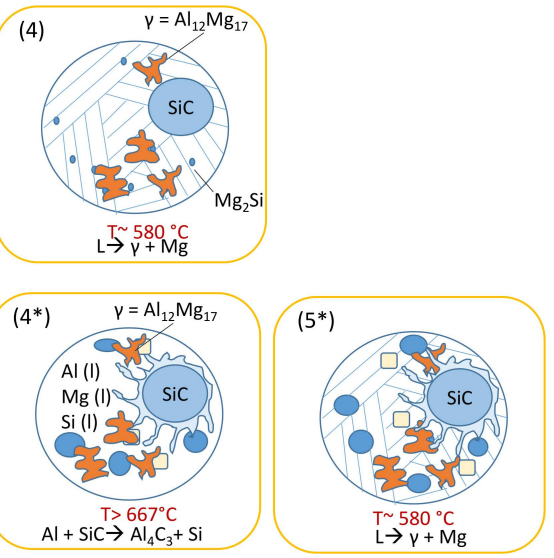

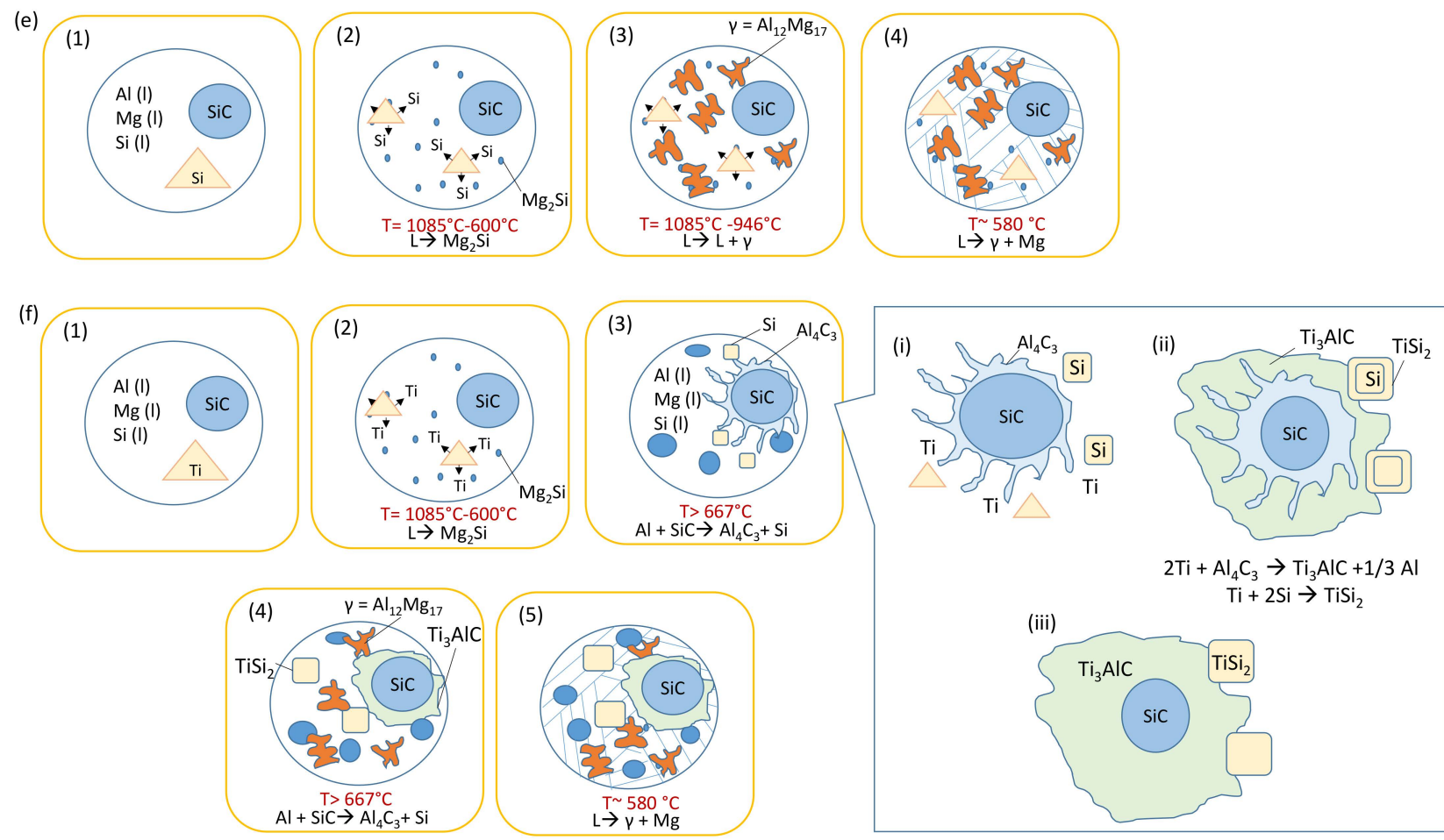

Figure 8. Schematic of the microstructure formation mechanism: (a) Al-Mg phase diagram; (b) Mg-Si phase diagram; (c) $\mathrm{Al} / \mathrm{SiC}$ microstructure formation mechanism (Mg-rich zone); (d) Al/SiC microstructure formation mechanism (Mg-poor zone); (e) Al40Si/SiC microstructure formation mechanism; (f) Al12Si20Ti/SiC micro- structure formation mechanism [24].

Liu et al. (2006) [21] investigated the fabrication of $\mathrm{Al} / \mathrm{Al}_{2} \mathrm{O}_{3}$ coatings on AZ91D magnesium alloy by pulsed Nd:YAG laser. The results show that, as in the previous cases, there is dilution. However, this dilution can be of great benefit to the wear resistance. Other authors found similar results [46,47].

The use of nano-size particles has been also studied. Reinforcement particles are considered nano-size ones when they are in a scale of 1 to $100 \mathrm{~nm}$. The use of nanocomposite coatings has several advantages from the point of view of the tribological properties because the nano particles contribute to increasing the wear and corrosion resistance. Chen et al. 2008 researched the effect of laser cladding aluminum metal matrix reinforced with nano $\mathrm{SiC}$ particles and, the same authors studied, in 2011, the effect of using nano- $\mathrm{Al}_{2} \mathrm{O}_{3}$ particles [48,49]. Nowadays, Sundaraselvan and Senthilkumar [50] have continued to work on these nano- $\mathrm{Al}_{2} \mathrm{O}_{3}$ composite coatings. They used a Nd: YAG laser to coat ZE41 magnesium substrates, and they achieved the successful fabrication of high wear resistance and high proportion reinforcement composite coatings.

Nowadays, rare earth oxides have generated great expectations. $\mathrm{Y}_{2} \mathrm{O}_{3}$ have been used as reinforcement of different metal matrix composites to refine the microstructure of the substrate and obtain higher wear and corrosion coatings. Zhu et al. [51] developed $\mathrm{Al}-\mathrm{Cu}$ matrix composite reinforced with $\mathrm{Y} 2 \mathrm{O} 3$ with improved properties. Nowadays, other authors still continue using these reinforcement with other matrixes [52-54].

\section{Laser Cladding and Other Techniques}

Recently, some research has combined laser cladding with other coatings techniques. In the case of the coatings on magnesium alloys, these techniques could decrease the heat in the molten pool using lower laser power and higher scanning speed as to be able to obtain coatings with improved properties and better characteristics (lower pores, lower dilution, etc). Yue et al. [35] achieved a stainless-steel coating on ZK60/SiC composite by using a two-step method, i.e., thermal spray and laser re-melting. Pei et al. [55] combined direct current pulse metal inert gas welding with laser cladding. As it can be seen in Figure 9, the 
first stage of the methodology is a welding process, and in a second stage laser cladding has been performed on AZ91D magnesium alloy to fabricate a gradient modified coating, containing an Al-Si interlayer and a Ni-Cr-Al top layer (a scheme of this microstructure is shown in the inset in Figure 9). The coating obtained has higher micro-hardness and better corrosion resistance. However, they did not completely avoid the magnesium dilution.

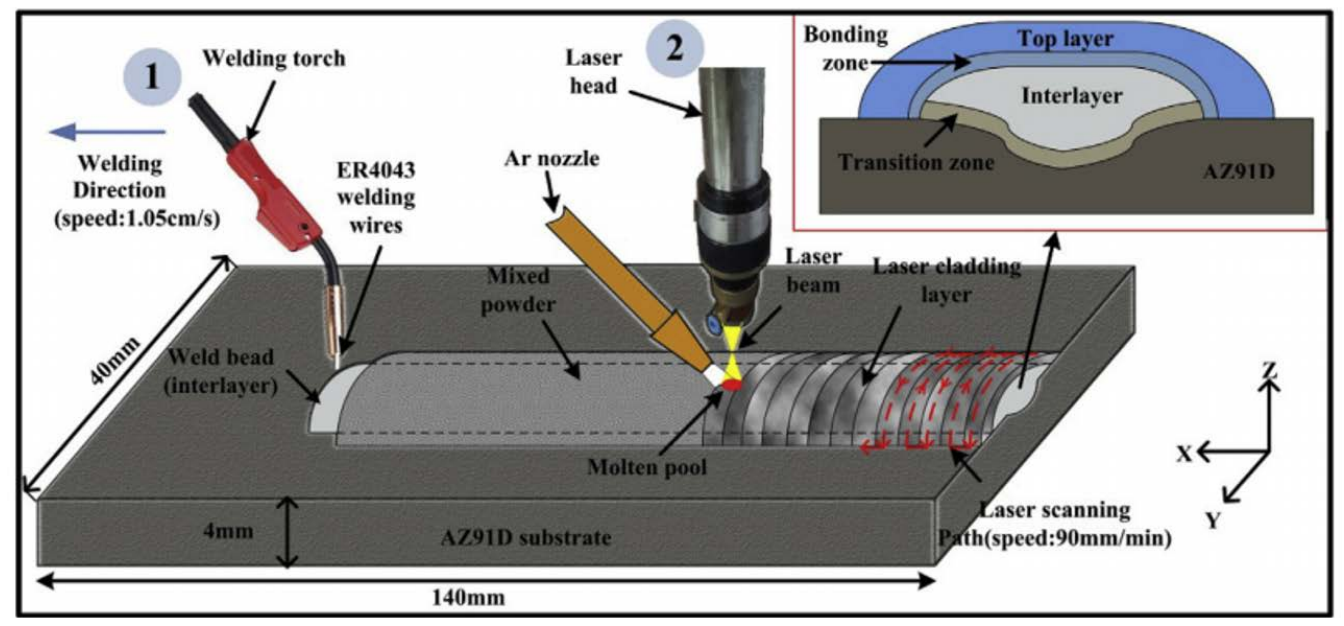

Figure 9. Schematic of the DC-PMIG welding process combined with the laser cladding process. Reprinted with permission from ref. [55]. Copyright 2021 Elsevier.

In the recent years, additive manufacturing has been the new revolution of the industry, and the research about 3D fabrication of metals is growing exponentially. However, magnesium additive manufacturing is in its first stages, due to its low melting point [56,57].

Direct laser deposition (DLD) is an additive manufacturing process to obtain 3D components. This technique is an evolution of the laser cladding technique. In laser cladding, a single layer is deposited instead, in DLD, multiple laser layers are deposited layer by layer to obtain the final 3D structure.

\section{Conclusions}

Laser cladding is an effective fabrication technique to obtain coatings on magnesium alloys. These coatings improved the substrate mechanical and tribological properties and in most cases, improved the corrosion behavior, however, more investigation is required due to the high possibility of the micro-cell formation resulting from the dilution between the coating and the substate.

The main problem of laser cladding technique used on magnesium alloys is the very low melting point of these alloys, that results in the evaporation of the substrate and/or high dilution and/or alloying between the coating and the substrate. For this reason, the analysis, optimization and control of the laser cladding parameters is crucial. In most cases, low laser power is necessary for obtaining lower dilution coatings. However, other combinations of laser parameters, mainly lower laser power and high scanning speed are possible. The specific parameters depend on the kind of laser used in the process (TEM mode, wavelength, spot size). In addition, changes in the carrying gas flow rate, powder feed rate, focal position or the kind of used laser result in changes in the characteristics of the coating-substrate system.

Additionally, it is possible to obtain different material coatings on magnesium alloys fabricated by laser cladding: pure metal, binary and ternary alloy, high entropy alloy, ceramics and metal matrix composites. However, improved properties coatings have been obtained when the coating material has similar physical properties to magnesium substrates. A high wettability and similar thermal expansion coefficient are desirable. The most used metals as laser cladding coatings are aluminum and their alloys (mainly binary alloys as Al-Si). In all these cases, different grade of dilution and reactivity between 
the coating and the substrate are observed and the formation of Al-Mg-Me compounds have been identified. However, the formation of these compounds has some benefits and, in most cases, increases the wear resistance and/or even the corrosion resistance. The use of aluminum alloy coatings improves the corrosion resistance of the substrate provided that the formation of anodic phases in the coating is controlled. To do this, the process parameters must be properly chosen. High scanning speeds together with low energies, reduce dilution and increase the cooling speed, preventing the diffusion of $\mathrm{Mg}$ in the coating and, therefore, reducing the tendency of the samples to suffer galvanic corrosion. Aluminum metal matrix composites reinforced with particles are the most used for developing composite coatings on magnesium alloys by laser cladding. The most used particles are $\mathrm{SiC}$ and $\mathrm{Al}_{2} \mathrm{O}_{3}$. Nowadays nano-particles are receiving growing interest. High entropy alloys and ceramics coatings on magnesium by laser cladding are also possible, nevertheless, the literature is little, and it is necessary to conduct more research about this topic.

Nowadays new possibilities are open with the combination of different techniques, such as welding process with laser cladding or the 3D fabrication using direct laser deposition as an evolution of laser cladding process.

Author Contributions: Conceptualization, A.R. and P.R.; methodology, A.R. and P.R.; investigation, A.R. and P.R.; writing — original draft preparation, A.R.; writing—review and editing, P.R.; funding acquisition, A.R. All authors have read and agreed to the published version of the manuscript.

Funding: This research was funded by: Comunidad de Madrid (ADITINANO 2020/00007/019).

Institutional Review Board Statement: Not applicable.

Informed Consent Statement: Not applicable.

Data Availability Statement: The study did not report any data.

Conflicts of Interest: The authors declare no conflict of interest.

\section{References}

1. Cole, G.; Sherman, A. Light weight materials for automotive applications. Mater. Charact. 1995, 35, 3-9. [CrossRef]

2. Ostrovsky, L.; Henn, Y. Present state and future of magnesium application in aerospace industry. In Proceedings of the International Conference "New Challenges in Aeronautics" ASTEC 07, Moscow, Russia, 19-22 August 2007; pp. 19-22.

3. Kulekci, M.K. Magnesium and its alloys applications in automotive industry. Int. J. Adv. Manuf. Technol. 2008, 39, 851-865. [CrossRef]

4. Zhong, M.; Liu, W. Laser surface cladding: The state of the art and challenges. Proc. Inst. Mech. Eng. Part C J. Mech. Eng. Sci. 2010, 224, 1041-1060. [CrossRef]

5. Das, A.K. Recent trends in laser cladding and alloying on magnesium alloys: A review. Mater. Today Proc. 2021, in press. [CrossRef]

6. Toyserkani, E.; Khajepour, A.; Corbin, S. Laser Cladding; CRC Press: Boca Raton, FL, USA, 2004.

7. Ignat, S.; Sallamand, P.; Grevey, D.; Lambertin, M. Magnesium alloys laser (Nd:YAG) cladding and alloying with side injection of aluminium powder. Appl. Surf. Sci. 2004, 225, 124-134. [CrossRef]

8. Yue, T.; Su, Y.; Yang, H. Laser cladding of Zr65Al7.5Ni10Cu17.5 amorphous alloy on magnesium. Mater. Lett. 2007, 61, 209-212. [CrossRef]

9. Huang, K.; Xie, C.; Yue, T.M. Microstructure of cu-based amorphous composite coatings on AZ91D magnesium alloy by laser cladding. J. Mater. Sci. Technol. 2009, 25, 492-498.

10. Yue, T.M.; Su, Y. Laser cladding of SiC reinforced Zr65Al7.5Ni10Cu17.5 amorphous coating on magnesium substrate. Appl. Surf. Sci. 2008, 255, 1692-1698. [CrossRef]

11. Su, Y.; Yue, T. Microstructures of the bonding area in laser cladded Zr-based amorphous alloy coating on magnesium. Mater. Today Commun. 2020, 25, 101715. [CrossRef]

12. Ignat, S.; Sallamand, P.; Grevey, D.; Lambertin, M. Magnesium alloys (WE43 and ZE41) characterisation for laser applications. Appl. Surf. Sci. 2004, 233, 382-391. [CrossRef]

13. Yang, L.; Li, Z.; Zhang, Y.; Wei, S.; Liu, F. Al-TiC in situ composite coating fabricated by low power pulsed laser cladding on AZ91D magnesium alloy. Appl. Surf. Sci. 2018, 435, 1187-1198. [CrossRef]

14. Wang, A.; Xia, H.; Wang, W.; Bai, Z.; Zhu, X.; Xie, C. YAG laser cladding of homogenous coating onto magnesium alloy. Mater. Lett. 2006, 60, 850-853. [CrossRef] 
15. Riquelme, A.; Rodrigo, P.; Escalera-Rodríguez, M.D.; Rams, J. Analysis and optimization of process parameters in Al-SiCp laser cladding. Opt. Lasers Eng. 2016, 78, 165-173. [CrossRef]

16. Carcel, B.; Sampedro, J.; Ruescas, A.; Toneu, X. Corrosion and wear resistance improvement of magnesium alloys by laser cladding with Al-Si. Phys. Procedia 2011, 12, 353-363. [CrossRef]

17. Lawrence, J.; Peligrad, A.; Zhou, E.; Li, L.; Morton, D. Prediction of melt depth in selected architectural materials during high-power diode laser treatment. Opt. Lasers Eng. 2001, 35, 51-62. [CrossRef]

18. Shi, J.; Zhu, P.; Fu, G.; Shi, S. Geometry characteristics modeling and process optimization in coaxial laser inside wire cladding. Opt. Laser Technol. 2018, 101, 341-348. [CrossRef]

19. Anjos, M.; Vilar, R.; Li, R.; Ferreira, M.; Steen, W.; Watkins, K. Fe-Cr-Ni-Mo-C alloys produced by laser surface alloying. Surf. Coat. Technol. 1995, 70, 235-242. [CrossRef]

20. Wang, A.; Yue, T. YAG laser cladding of an Al-Si alloy onto an Mg/SiC composite for the improvement of corrosion resistance. Compos. Sci. Technol. 2001, 61, 1549-1554. [CrossRef]

21. Liu, Y.; Guo, Z.; Yang, Y.; Wang, H.; Hu, J.; Li, Y.; Chumakov, A.; Bosak, N. Laser (a pulsed Nd:YAG) cladding of AZ91D magnesium alloy with $\mathrm{Al}$ and $\mathrm{Al}_{2} \mathrm{O}_{3}$ powders. Appl. Surf. Sci. 2006, 253, 1722-1728. [CrossRef]

22. Liu, J.; Yu, H.; Chen, C.; Weng, F.; Dai, J. Research and development status of laser cladding on magnesium alloys: A review. Opt. Lasers Eng. 2017, 93, 195-210. [CrossRef]

23. Chen, E.; Zhang, K.; Zou, J. Laser cladding of a Mg based Mg-Gd-Y-Zr alloy with Al-Si powders. Appl. Surf. Sci. 2016, 367, 11-18. [CrossRef]

24. Riquelme, A.; Rodrigo, P.; Escalera-Rodríguez, M.D.; Rams, J. Characterisation and mechanical properties of $\mathrm{Al} / \mathrm{SiC}$ metal matrix composite coatings formed on ZE41 magnesium alloys by laser cladding. Results Phys. 2019, 13, 102160. [CrossRef]

25. Volovitch, P.; Masse, J.; Fabre, A.; Barrallier, L.; Saikaly, W. Microstructure and corrosion resistance of magnesium alloy ZE41 with laser surface cladding by Al-Si powder. Surf. Coat. Technol. 2008, 202, 4901-4914. [CrossRef]

26. Fabre, A.; Masse, J. Friction behavior of laser cladding magnesium alloy against AISI 52100 steel. Tribol. Int. 2012, 46, 247-253. [CrossRef]

27. Yue, T.; Wang, A.; Man, H. Corrosion resistance enhancement of magnesium ZK60/SiC composite by Nd:YAG laser cladding. Scr. Mater. 1999, 40, 303-311. [CrossRef]

28. Yang, Y.; Wu, H. Improving the wear resistance of AZ91D magnesium alloys by laser cladding with Al-Si powders. Mater. Lett. 2009, 63, 19-21. [CrossRef]

29. Qian, M.; Li, D.; Liu, S.; Gong, S. Corrosion performance of laser-remelted Al-Si coating on magnesium alloy AZ91D. Corros. Sci. 2010, 52, 3554-3560. [CrossRef]

30. Gao, Y.; Wang, C.; Pang, H.; Liu, H.; Yao, M. Broad-beam laser cladding of Al-Cu alloy coating on AZ91HP magnesium alloy. Appl. Surf. Sci. 2007, 253, 4917-4922. [CrossRef]

31. Mei, Z.; Guo, L.; Yue, T. The effect of laser cladding on the corrosion resistance of magnesium ZK60/SiC composite. J. Mater. Process. Technol. 2005, 161, 462-466. [CrossRef]

32. Chen, C.; Wang, M.; Wang, D.; Jin, R.; Liu, Y. Laser cladding of Al + Ir powders on ZM5 magnesium base alloy. Rare Met. 2007, 26, 420-425. [CrossRef]

33. Wang, C.; Li, T.; Yao, B.; Wang, R.; Dong, C. Laser cladding of eutectic-based Ti-Ni-Al alloy coating on magnesium surface. Surf. Coat. Technol. 2010, 205, 189-194. [CrossRef]

34. Wang, C.; Chen, Y.; Li, T.; Yao, B. Composition design and laser cladding of Ni-Zr-Al alloy coating on the magnesium surface. Appl. Surf. Sci. 2009, 256, 1609-1613. [CrossRef]

35. Yue, T.M.; Hu, Q.; Mei, Z.; Man, H. Laser cladding of stainless steel on magnesium ZK60/SiC composite. Mater. Lett. 2001, 47, 165-170. [CrossRef]

36. Yue, T.M.; Xie, H.; Lin, X.; Yang, H.; Meng, G. Solidification behaviour in laser cladding of AlCoCrCuFeNi high-entropy alloy on magnesium substrates. J. Alloys Compd. 2014, 587, 588-593. [CrossRef]

37. Meng, G.; Liu, X.; Qiu, J.; Wang, B.; Zhao, K. Growth Morphology of CuMg 2 in Laser Forming of AlCoCrCuFeNi Coating on Mg. Adv. Eng. Res. 2017, 146, 162-165.

38. Meng, G.; Yue, T.; Lin, X.; Yang, H.; Xie, H.; Ding, X. Laser surface forming of AlCoCrCuFeNi particle reinforced AZ91D matrix composites. Opt. Laser Technol. 2015, 70, 119-127. [CrossRef]

39. Meng, G.; Lin, X.; Xie, H.; Wang, C.; Wang, S.; Ding, X. Reinforcement and substrate interaction in laser surface forming of $\mathrm{AlCoCrCuFeNi}$ particle reinforced AZ91D matrix composites. J. Alloys Compd. 2016, 672, 660-667. [CrossRef]

40. Gao, Y.-L.; Wang, C.-S.; Yao, M.; Liu, H.-B. The resistance to wear and corrosion of laser-cladding $\mathrm{Al}_{2} \mathrm{O}_{3}$ ceramic coating on $\mathrm{Mg}$ alloy. Appl. Surf. Sci. 2007, 253, 5306-5311. [CrossRef]

41. Zheng, B.; Chen, X.; Lian, J. Microstructure and wear property of laser cladding Al + SiC powders on AZ91D magnesium alloy. Opt. Lasers Eng. 2010, 48, 526-532. [CrossRef]

42. Majumdar, J.; Chandra, B.; Galun, R.; Mordike, B.; Manna, I. Laser composite surfacing of a magnesium alloy with silicon carbide. Compos. Sci. Technol. 2003, 63, 771-778. [CrossRef]

43. Zheng, B.; Hu, W. Enhanced wear property of magnesium alloy with $\mathrm{Al}+\mathrm{SiC}$ coating by laser cladding. High Power Laser Part Beams 2014, 26, 059003. [CrossRef] 
44. Riquelme, A.; Rodrigo, P.; Escalera-Rodriguez, M.; Rams, J. Evaluation of the Wear Resistance and Corrosion Behavior of Laser Cladding $\mathrm{Al} / \mathrm{SiC}$ Metal Matrix Composite Coatings on ZE41 Magnesium Alloy. Coatings 2021, 11, 639. [CrossRef]

45. Arthanari, S.; Li, Y.; Nie, L.; Guan, Y.; Yang, S. Microstructural evolution and properties analysis of laser surface melted and $\mathrm{Al} / \mathrm{SiC}$ cladded magnesium-rare earth alloys. J. Alloys Compd. 2020, 848, 156598. [CrossRef]

46. Jun, Y.; Sun, G.; Wang, H.-Y.; Jia, S. Laser (Nd:YAG) cladding of AZ91D magnesium alloys with Al+Si+Al2O3. J. Alloys Compd. 2006, 407, 201-207. [CrossRef]

47. Qian, J.; Yin, Y.; Li, T.; Hu, X.; Wang, C.; Li, S. Structure, micro-hardness and corrosion behaviour of the $\mathrm{Al}_{-} \mathrm{Si} / \mathrm{Al}_{2} \mathrm{O}_{3}$ coatings prepared by laser plasma hybrid spraying on magnesium alloy. Vacuum 2015, 117, 55-59. [CrossRef]

48. Chen, C.; Zhang, M.; Chang, Q.M.; Zhang, S.; Ma, H.Y.; Yan, W.Q.; Wang, M. Laser cladding of ZM5 magnesium base alloy with $\mathrm{Al}+\mathrm{Nano}-\mathrm{SiC}$ powder. Lasers Eng. 2008, 18, 85-94.

49. Chen, C.; Cao, Q.; Xu, X.; Zhang, M.; Zhang, S. Laser cladding of Al+nano- $\mathrm{Al}_{2} \mathrm{O}_{3}$ powder on ZM5 mganesium alloy. Adv. Mater. Res. 2011, 291, 1429-1432. [CrossRef]

50. Sundaraselvan, S.; Senthilkumar, N.; Tamizharasan, T.; Naveen Sait, A. Surface modification of AZ61 Magnesium Alloy with $\mathrm{Nano} \mathrm{TiO}_{2} / \mathrm{Al}_{2} \mathrm{O}_{3}$ using Laser Cladding Technique. Mater. Today Proc. 2020, 21, 717-721. [CrossRef]

51. Zhu, R.; Li, Z.; Li, X.; Sun, Q. Microstructure and properties of the low-power-laser clad coatings on magnesium alloy with different amount of rare earth addition. Appl. Surf. Sci. 2015, 353, 405-413. [CrossRef]

52. Chen, C.J.; Cao, Q.; Xu, X.; Zhang, M. Effect of $\mathrm{Y}_{2} \mathrm{O}_{3}$ Addition on the Microstructure and Corrosion Behaviour of Laser Cladding of Al Powder on ZM5 Magnesium Alloys. Adv. Mater. Res. 2011, 314-316, 1867-1870. [CrossRef]

53. Bu, R.; Jin, A.; Sun, Q.; Zan, W.; He, R. Study on laser cladding and properties of AZ63-Er alloy for automobile engine. J. Mater. Res. Technol. 2020, 9, 5154-5160. [CrossRef]

54. Yang, L.; Li, Z.; Zhang, Y.; Wei, S.; Wang, Y.; Kang, Y. In-situ TiC-Al3Ti reinforced Al-Mg composites with Y2O3 addition formed by laser cladding on AZ91D. Surf. Coat. Technol. 2020, 383, 125249. [CrossRef]

55. Pei, X.; Li, Z.; Zhang, Y.; Wei, S.; Yang, L.; Wang, Y. A gradient Al/Ni-Cr-Al layer formed by direct current pulse metal inert gas welding combined laser cladding on AZ91D magnesium alloy. Vacuum 2019, 165, 86-95. [CrossRef]

56. Karunakaran, R.; Ortgies, S.; Tamayol, A.; Bobaru, F.; Sealy, M.P. Additive manufacturing of magnesium alloys. Bioact. Mater. 2020, 5, 44-54. [CrossRef] [PubMed]

57. Tokarev, M.S.; Trofimov, N.V.; Leonov, A.A.; Alikhanyan, A.A. Methods Additive Manufacturing of Magnesium Alloys (review). 2021. Available online: https://www.sciencegate.app/app/document/download/10.18577/2307-6046-2021-0-6-3-16 (accessed on 10 November 2021). 